\title{
Nietzsche e a filosofia como maneira de viver a amizade
}

VERKERK, Willow. Nietzsche and Friendship, Bloomsbury, London-New York, 2019.

\section{Gianfranco Ferraro*}

A investigação sobre o pensamento de Nietzsche em torno da amizade não é um tópico habitual na Nietzscheforschung e o livro de Willow Verkerk tem o mérito indubitável de mapear as reflexões do filósofo alemão neste domínio, oferecendo um espectro de leitura relacionado com o mais recente debate filosófico. Se, por um lado, não existe um livro de Nietzsche focado neste tema, são vários os lugares em que Nietzsche fala, ou deixa falar algumas das suas máscaras, sobre a amizade e a importância da amizade para a própria filosofia. O foco do livro de Verkerk, que segue vários outros textos escritos da autora sobre o mesmo tópico, é exatamente a recuperação deste lado do pensamento nietzschiano. Se, por um lado, Verkerk parece ligar este aspecto a toda a tradição da "amizade filosófica" que, desde Platão e atravessando as escolas helenísticas, em particular a estóica e a epicurista, chega ao humanismo renascentista francês e italiano, e, através deste, ao próprio Nietzsche, por outro lado, consegue colocar este lado da reflexão de

\footnotetext{
*Universidade Nova de Lisboa. Portugal. Correio eletrônico: gianfranco.ferraro@gmail.com. ORCID: https://orcid.org/0000-0003-4449-6127

Esta resenha foi escrita com o apoio da FCT, Fundação para a Ciência e a Tecnologia, Portugal. Todas as traduções do texto de Verkerk são minhas. Agradeço a Vanessa Rôla pelo cuidado e a atenção que teve na revisão deste texto.
} 
Notas sobre um estudo de fontes: Ribot, Nietzsche e a psicofisiologia francesa do século XIX

Nietzsche no quadro da influência que o filósofo teve no contexto do debate filosófico continental atual, onde o tópico da amizade voltou a ser crucial. Nesse sentido, podemos indicar pelo menos quatro linhas de pesquisa contemporânea que abordam o tópico da amizade, não só como objeto de investigação, como também enquanto lugar do próprio exercício filosófico. Em primeiro lugar, não se pode esquecer, no seio da tradição da Desconstrução, a reflexão de Jacques Derrida em as Políticas da amizade (Derrida, 2003), livro editado em 1994 e que assinala a viragem mais significativamente ético-política do filósofo francês. Um livro cuja reflexão encontra, de várias maneiras, a reflexão do Nietzsche sobre a amizade e que redescobre Nietzsche como autor crucial para uma reflexão crítica de caráter ético e político (vale a pena mencionar, neste contexto, os livros da Sarah Kofman, também ela ligada ao pensamento da desconstrução, sobre o último Nietzsche). Em segundo lugar, é preciso destacar a reflexão feminista, na qual a própria Verkerk se inscreve. Uma reflexão na qual, a partir dos primeiros anos da década de 80, com as reflexões de Luce Irigaray e, em épocas mais recentes, de Judith Butler, Nietzsche foi sempre estudado como autor essencial para uma compreensão das relações intergênero, assim como para uma reflexão sobre a genealogia das instituições afetivas ocidentais. Neste último contexto, vale a pena lembrar também a reflexão de Babette Babich. Em terceiro lugar, importa destacar a reflexão sobre Nietzsche, assim como sobre a própria prática da filosofia, desenvolvida por Gilles Deleuze e cujos resultados podem ser ainda hoje observados nos âmbitos de investigação que se espelham na reflexão ética sobre o transhumanismo ou o pós-humanismo. Por fim, em quarto lugar, é preciso ainda lembrar todo o horizonte do pensamento contemporâneo que, a partir da reflexão de Pierre Hadot (2014) sobre a "filosofia como maneira de viver", se focou nas tradições e nos autores onde se torna visível uma aproximação entre filosofia e vida concreta. Também nesse caso as referências ao pensamento antigo, em particular aos estóicos e aos 
epicuristas, se tornam decisivas, sendo que, na interpretação de Hadot, estas vertentes filosóficas - e, aliás, praticamente todas as escolas filosóficas antigas - estão diretamente ligadas a problemáticas existenciais e têm o foco não só sobre a reflexão teórica, como também sobre as maneiras de viver. No quadro desta investigação, Hadot entrevê a persistência desta modalidade filosófica também na modernidade, uma modalidade que se reflete em autores caracterizados precisamente por uma recepção, ou uma redescoberta, dos autores antigos: Montaigne, Espinosa, Kierkegaard, Schopenhauer e o próprio Nietzsche. O encontro desta abordagem com a mais recente investigação da Nietzscheforschung internacional deu origem a uma recente e promissora reflexão de especialistas, focada sobre os aspectos do pensamento nietzschiano mais ligados a este âmbito: Keith Ansell-Pearson e Michael Ure, autores de referência para a própria Verkerk, e a nova geração de intérpretes como Martine Béland, em âmbito francófono, e Marta Faustino, em âmbito lusófono, ambas influenciadas, por sua vez, pela reflexão de Werner Stegmaier e Patrick Wotling.

É preciso, portanto, ter em conta este âmbito complexo de reflexão sobre o próprio conceito de amizade filosófica e sobre as mais recentes abordagens a Nietzsche, de modo a enquadrar a proposta de Verkerk.

O ponto de partida da análise da autora é a leitura, feita por Nietzsche, dos autores antigos e modernos que mais se questionaram sobre a questão da amizade, assim como sobre a "reavaliação" da função filosófica da amizade (Verkerk, 2019, p. XI). É importante sublinhar, também, como Verkerk relaciona esta reavaliação feita por Nietzsche com o seu diagnóstico do niilismo e da falta provocada pela "morte de Deus" na cultura ocidental. Mais concretamente, Verkerk explicita como a reconsideração nietzschiana da amizade, enquanto conceito e prática filosófica, se fundamenta nas "metodologias do espírito livre" (p. 2) e na insistência com que em várias ocasiões Nietzsche escreve sobre um "wir" [nós], insistência 
Notas sobre um estudo de fontes: Ribot, Nietzsche e a psicofisiologia francesa do século XIX

que originou várias interpretações. Se, historicamente, Nietzsche foi considerado um filósofo individualista, o que seria testemunhado também nos objetivos da sua reflexão sobre o espírito livre, por outro lado, Verkerk chama a atenção para as considerações nietzschianas relativas à ligação entre a amizade e a "alegria partilhada" (p. 2), e à virtude enquanto fruto de doação. Três são, em resumo, os tipos de amizade que Verkerk sublinha em Nietzsche, ao longo dos três períodos do seu percurso intelectual: a amizade alegre, a amizade agonística e a amizade que doa. Cruciais - não só para o próprio resultado do livro - são também as perguntas de partida colocadas por Verkerk ("Em que diferem, para Nietzsche, amizade e amor?"; "Qual é a relação entre amizade e superação de si?"; "De que forma é que os escritos de Nietzsche nos ajudam a repensar o sentido da amizade hoje?", p.2).

É no primeiro capítulo, "O dom literário da amizade de Nietzsche: ler Nietzsche como um amigo alegre, agonístico e capaz de doar" [Nietzsche's Literary Gift of Friendship: Reading Nietzsche as a Joyful, Agonistic, and Bestowing Friend] (pp. 9-28), que a autora aborda as próprias práticas de escrita de Nietzsche enquanto forma de interação amical para com o leitor. São particularmente sublinhados, neste capítulo, os aspectos do pensamento de Nietzsche mais relacionados com a terapêutica, enquanto prática filosófica focada nas formas de vida. $\mathrm{O}$ ato de escrita, assim como alguns dos instrumentos metodológicos definidos por Nietzsche - a própria genealogia - são, nesse sentido, reconduzidos a uma prática de recriação das relações, premissa para o surgimento dos "espíritos livres" e "filósofos do futuro" que Nietzsche pretende evocar. Os próprios usos da dialética, da provocação e da genealogia, são indicados por Verkerk como instrumentos endereçados a uma autossuperação dos próprios interlocutores e a um questionamento crítico das modalidades de interação com a tradição e com as crenças pessoais. Ler Nietzsche parece implicar, nesse sentido, quase um "pacto parresiástico" semelhante ao que, na tradição antiga descrita por 
Michel Foucault (2020) - grande e inesperada ausência entre as referências do livro - implicava a aceitação mútua de uma crítica e de uma verdade nunca neutra, antes pelo contrário, capaz de alterar e de transformar a maneira de viver dos interlocutores. A escrita de Nietzsche implicaria por isso mesmo [GM/GM, Prólogo, 8, KSA 5.256] uma "arte de ler", isto é, aquele "ruminar" que só pode ser característico de uma leitura lenta, capaz de introjetar os conteúdos e até as revelações mais dolorosas para o equilíbrio individual. É nesse sentido que Nietzsche pode ser interpretado como "um amigo agonístico que oferece o dom para incitar a questionar-se" (Verkerk, 2019, p. 10). Fundamentando-se no uso dos prefácios de Nietzsche, para além da elaboração de Ecce Homo (sem dúvida uma das considerações mais originais do livro), Verkerk propõe uma leitura abrangente, complexa e unitária das obras do segundo e do terceiro períodos (cf. p. 14). É interessante o destaque que a autora dá, em particular, a uma mudança nas referências aos pensadores antigos da amizade, entre Humano, demasiado humano e as últimas obras, mais focadas em objetivos críticos: no período que separa estes momentos do pensamento nietzschiano, consumar-se-ia, portanto, um afastamento da referência ao epicurismo - crucial na primeira e segunda parte da parábola intelectual de Nietzsche - e uma aproximação, cada vez mais fundamentada, aos estóicos (cf. p. 15). Assim, a verdadeira "conversão" terapêutica da qual testemunha Humano demasiado humano - e que Nietzsche sublinha no capítulo de Ecce Homo dedicado à reflexão sobre esta obra - não seria uma conversão solitária, mas, pelo contrário, uma conversão aberta, isto é, a amigos identificados nos espíritos livres do futuro e, por sua vez, provocada por amigos identificados nos espíritos livres do passado. Nesse quadro, Verkerk desenvolve uma análise de Assim falava Zaratustra, onde a "grande saúde", incorporada por Zaratustra, é representada por si mesma como uma inesgotável prática de doação. Adicionalmente, o próprio Zaratustra seria, com o seu peculiar estilo narrativo, uma tentativa de Nietzsche "de ins- 
Notas sobre um estudo de fontes: Ribot, Nietzsche e a psicofisiologia francesa do século XIX

pirar os seus leitores a começar um processo de autossuperação e de acumulação da saúde" (p. 19). Nesse sentido, Zaratustra seria "o coração da filosofia da amizade de Nietzsche" (p. 19): o próprio subtítulo, "Um livro para todos e para ninguém", seria apenas testemunho de Nietzsche não ter ainda encontrado os espíritos livres que procurava, e, portanto, uma forma específica de provocação dos próprios leitores. Uma resposta ao apelo do texto pode, portanto, ser dada só através de um "questionar, desafiar e, por fim, responder ao texto como sendo um amigo agonístico" (p. 20). Com Além de bem e do mal abrir-se-ia, em Nietzsche, uma técnica de apelo diferente: "Nietzsche escreve para recrutar companheiros que o ajudem nesse efeito, mesmo que isto seja póstumo. Para convencer os leitores apropriados a juntar-se a ele neste ato, Nietzsche escreve com um objetivo desconstrutivo que envolve a reforma do seu projeto de abalar conceitos morais" (p. 20). Verkerk sublinha também a ênfase que o próprio Nietzsche põe na forma como espera ser lido, quase uma pedagogia do método que é preciso adotar para poder entrar em relação com os seus textos. Contudo, desafiando uma parte da crítica que interpreta os textos de Nietzsche só como multidirecionados, protrépticos, metodológicos, Verkerk afirma neles a presença quer de uma vertente propriamente protréptica, quer de uma vertente filosófica. Estilo e conteúdo parecem constituir-se, portanto, como as duas faces de um constante apelo à autoformação de si: o estilo performativo explicar-se-ia, por si mesmo, a partir desta ambição transformativa e ligada a uma "filosofia como maneira de viver", que parece atravessar a obra inteira como uma unidade de perspectiva. Também o frequente uso do "nós" da parte de Nietzsche pode, segundo a autora, ser interpretado como uma forma de recriação de uma conversa "direta e pessoal" (p. 25), uma "figura transicional", segundo a interpretação de Van Tongeren, que tem como alvo a criação de uma companhia atravessada por uma "erótica" atrativa ou, dependendo dos casos, recusável. Tratar-se-ia, enfim, de uma "dicotomia de superfície entre aqueles 
que são libertados e aqueles que não o são". Esta dicotomia, que à primeira vista parece por vezes implicar uma oposição amigo-inimigo, resolve-se sempre, segundo Verkerk, num apelo agonístico à contestação e à refinação da consciência intelectual: mais do que à fundação de uma comunidade profética, esta dicotomia seria um instrumento provocatório, isto é, oferecido por Nietzsche aos seus leitores com o fim de "construir novos valores e novas "maneiras de viver" (p. 26). As influências da abordagem prática à filosofia de Montaigne, de Emerson e dos helenistas antigos parece fundamentar a identificação da prática filosófica nietzschiana com uma prática psicológica e, conforme a interpretação de Pierre Hadot, com uma "arte da vida" que envolve não só os aspectos teóricos como a existência no seu todo (Cf. Verkerk, 2019. p. 26). "Agonista psicólogo", Nietzsche propõe uma atitude corajosa para a desconstrução das virtudes consideradas socialmente aceitáveis, como a piedade ou o altruísmo. É só através da compreensão das motivações reais e dos impulsos mais escondidos que se pode avançar para uma forma de relacionamento para consigo próprio e para com os outros verdadeiramente digna, isto é, de espíritos livres. Este caminho médico, conduzido através de diagnoses, prognoses e terapêuticas, parece, porém, caracterizar-se, segundo Verkerk, por uma forma cooperativa e nunca solitária: o estilo, muitas vezes apelativo e interrogante de Nietzsche testemunharia, também nesse sentido, uma aproximação à tradição filosófica individuada por Hadot.

No segundo capítulo, A reavaliação de Nietzsche da amizade [Nietzsche's Re-evaluation of Friendship] (pp. 29-65), Verkerk sublinha a presença de um pensamento da amizade em toda a parábola intelectual de Nietzsche. Contrariamente a alguns intérpretes (Abbey), que abordaram o tópico evidenciando a sua presença quase exclusiva nos escritos do segundo período, Verkerk esclarece como é a própria concepção de amizade como lugar de prazer e harmonia que Nietzsche coloca em causa, por exemplo, nas suas últimas obras, abrindo caminho a uma transformação do próprio 
Notas sobre um estudo de fontes: Ribot, Nietzsche e a psicofisiologia francesa do século XIX

conceito e relacionando-o mais com os aspectos agonísticos e críticos que este possuía na Antiguidade (cf. p. 30). As interpretações que avançam uma imagem de Nietzsche misantropo ou, pelo menos, anárquico-individualista, são criticadas por Verkerk a partir da própria procura - que se pode evidenciar em inúmeras ocasiões - de um tipo de amizade sem dúvida aristocrática, "hierárquica", que permita, de alguma forma, um afastamento das incumbências e dos ruídos da sociedade. O próprio conceito de espírito livre testemunha a vocação claramente autocentrada, mas nunca autorreferencial, deste tipo de humanidade, da qual, porém, são excluídas as mulheres enquanto seres constrangidos ao longo de milênios a incorporar uma atitude de voluntária servidão. Em Zaratustra, um dos aspectos já abordados relacionado com os espíritos livres volta a aparecer na junção que Zaratustra faz entre seguidores dele e seguidores de si próprios: abandonando as metáforas, indivíduos capazes de manter e de desenvolver - segundo o próprio ensino profético - uma instância crítica para consigo, os outros e o próprio "mestre". Conforme o que o próprio Nietzsche afirma, no Prefácio a Humano demasiado humano I, os espíritos livres teriam acabado por tomar o lugar dos amigos físicos perdidos ao longo da vida. A experiência existencial de Nietzsche, confirma a autora, tem inevitavelmente um peso sobre a sua reflexão relativa à amizade: é verdade, porém, também o contrário, sendo que o objetivo ou a imagem de amigo em Nietzsche parece ter, em ambos os casos, as mesmas características: "para se ser um amigo nietzschiano", conclui Verkerk, "é preciso ser-se capaz de prover alguma oposição e isto requer compreensão de si. Um companheiro diferente, cujas crenças dependem do outro, é incapaz disto" (p. 35). Os companheiros de Zaratustra, pelo contrário, são caracterizados por "grandes capacidades de alegria, transformação e criatividade” (p. 36). Verkerk sublinha, neste sentido, um eco epicurista na concepção da amizade em Zaratustra, assim como em A gaia ciência: não é tanto a partilha da dor (Mitleiden) mas sim a partilha da alegria 
(Mitfreude) que "faz os amigos". A amizade aparece, neste sentido, constitutivamente ligada à afirmação de si: através de uma prática amical afirmativa, enraizada na alegria, cada um dos amigos pode criar uma experiência de plenitude em oposição às atitudes fracas da decadência. Através desta forma de amizade, catártica em alguns aspectos, é a própria sensação sombria da morte individual como destino último a ser revista e transformada. A inimizade caberia, portanto, dentro desta forma de amizade agônica, permitindo uma maior atitude no governo de si e, ao mesmo tempo, o crescimento recíproco - sobre uma base de igualdade - da atitude amical, na qual as formas de competição aparecem como desnecessárias. A ética nietzschiana da amizade parece, portanto, assentar sobre três aspectos: a partilha de um objetivo ou de uma atividade comum, a recusa da incompatibilidade entre amizade e interesse pessoal e o valor social da autossuperação (cf. p. 40). Uma ética que não se baseia no alvo da verdade, mas num processo de conhecimento sem fim. Ao mesmo tempo, trata-se de uma ética que não ultrapassa o interesse egoístico: uma amizade puramente altruística acaba por colocar em causa o respeito de si, que, no limite, deve até ser posto como premissa para uma amizade livre. Comentando o parágrafo de Assim falava Zaratustra intitulado "Sobre o amigo", Nietzsche destaca uma proporcionalidade direta entre a intimidade e a capacidade de lutar com o amigo. Por outras palavras, Verkerk sublinha como o amigo surge como o indivíduo capaz de aceitar, sem cortar os laços da amizade, um amigo que ocasionalmente se torna, quase dialeticamente, inimigo. A amizade canaliza, desta forma, as forças destruidoras e o próprio instinto de crueldade que é preciso, antes de mais, aceitar como componente decisiva em si e nos outros. A prática da amizade nietzschiana permite extrair a toxicidade deste instinto tornando-o, pelo contrário, originador de formas de vida afirmativas e de novas energias vitais: "Para aprender algo de novo e não ficar com o que é familiar, Nietzsche afirma que é importante desenvolver uma severidade para consigo que re- 
Notas sobre um estudo de fontes: Ribot, Nietzsche e a psicofisiologia francesa do século XIX

cuse a resistência interior à mudança" (p. 46). A amizade adquire, assim, o sentido de uma prática de conhecimento dos "caminhos secretos" da subjetividade (MA I/ HH I 491, KSA 2.318) e de superação partilhada dos limites individuais. Extremamente importante, por fim, o parágrafo dedicado à análise da amizade como prática agonística (cf. pp. 48-51): Verkerk coloca em destaque a diferença, sublinhada por Nietzsche, entre o agôn homérico, baseado numa forma de "desafio cooperativo", e a dialética socrática, onde o adversário acaba por ser humilhado. Contrariamente, o que está em questão na relação agonística é a excelência da própria relação, "uma espécie de terceira maneira de ser partilhada que vem a ser através do estar juntos dos amigos" (p. 50): concordando com Acampora, Verkerk sublinha como a diferença principal entre agôn homérico e agonismo nietzschiano consiste nos diferentes objetivos dos dois agonismos - no primeiro caso a glória, no segundo a transformação de valores. A virtude essencial é constituída pela Redlichkeit [FW/GS 335, KSA 3.564], que, de qualquer forma, tem de ser mediada através das necessidades prioritárias colocadas pela própria vida. Em Zaratustra, Nietzsche destaca também a importância da solidão para atingir a virtude: de que forma, então, pergunta-se Verkerk, a amizade pode diferenciar-se do "mercado" ao qual está exposto o indivíduo? Só no momento em que consegue ser uma prática capaz de ativar ou de reconhecer no outro uma certa maneira de ser übermenschlich. O super-homem, ou para-além-do-homem, seria, nesse sentido, mais uma figura provocatória de Nietzsche, apta a evocar uma transvaloração dos valores: " $\mathrm{O}$ super-homem é um símbolo que fornece uma estrutura para a amizade e encoraja uma luta afirmativa" (Verkerk, 2019, p. 61). Por outro lado, há práticas que acabam por empobrecer a amizade, sublinha Verkerk, como a expressão de piedade, sempre ligada a sentimentos não saudáveis, de falta de esperança, e como a ansiedade para com a morte, que o sofrimento do outro acentua. Em conformidade com a análise de Michael Ure, Verkerk destaca a relação en- 
tre piedade e sentimento narcisístico de voyeurismo, provocado pela "diminuição" do outro. A amizade deve, portanto, afastar-se deste sentimento, focando-se numa partilha centrada na reflexão e no trabalho comum de autossuperação. A autora dedica, por fim, algumas reflexões à interrupção das amizades, que se torna necessária para Nietzsche quando estas práticas acabam por restringir a liberdade do indivíduo ou se tornam estagnadas (cf. p. 64). Como explicitado em A gaia ciência 279, a interrupção da amizade, o devir-estrangeiro dos amigos, não implica a perda da memória sagrada, da própria amizade e do "exercício" agônico que esta representou para a autossuperação: tendo sido uma prática focada na transformação dos sujeitos envolvidos, estes continuam a incorporar nos próprios atos, e não é simplesmente uma memória abstrata, o lugar passado de encontro. Também nesse caso, Verkerk destaca o caráter da amizade enquanto treino constante, "exercício", exatamente no sentido de Hadot na sua genealogia da filosofia como maneira de viver: "A amizade nietzschiana é uma expressão do que Pierre Hadot descreve como 'arte da vida' filosófica"” (p. 65).

No terceiro capítulo, Do devir o que somos: o conceito terapêutico de Nietzsche do si próprio [On Becoming What One is: Nietzsche's Therapeutic Concept of the Self] (pp. 67-97), Verkerk sublinha a importância da compreensão do conceito nietzschiano de si próprio para abordar as características da noção de amizade. A autora foca-se em particular na análise das três versões das "hipóteses sobre a alma", de Nietzsche: a tese biológica, a social e a psico-ontológica. No primeiro caso, Verkerk foca-se na mistura entre componentes culturais e bio-genealógicos para a definição de um si próprio, destacando a maneira como Nietzsche sublinha a importância das formas culturais - como a dietética - para o desenvolvimento de determinadas características biológicas e, reciprocamente, de determinadas aquisições biológicas ou ambientais para a definição de determinadas formas biológicas. Não se pode fugir à centralidade do corpo como álveo de criação dos comporta- 
Notas sobre um estudo de fontes: Ribot, Nietzsche e a psicofisiologia francesa do século XIX

mentos, e a própria concepção do corpo como "grande razão" mostra este aspecto. Verkerk assume a noção nietzschiana do ser como algo intimamente precário, instável, e por isso mesmo naturalmente aberto à modificação pela intervenção de práticas de partilha, como a própria amizade. A autossuperação acaba, portanto, por ser a verdadeira estrutura da vida, conectada com a vontade de poder (cf. p. 95).

O quarto capítulo, Nietzsche e Aristóteles sobre o carácter, a virtude e os limites da amizade [Nietzsche and Aristotle on Character, Virtue, and the Limits of Friendship] (pp. 99-123), chega de modo um pouco ex abrupto para o leitor. Nele Verkerk desenvolve uma comparação entre as noções de amizade em Nietzsche e Aristóteles, apontando a eventual influência do segundo sobre o filósofo alemão e também a diferença fundamental relativa à procura de uma perfeição que em Nietzsche nunca é definitiva. $\mathrm{O}$ capítulo parece ser o mais fraco do livro, sendo que Verkerk não oferece uma análise filológica ou histórico-crítica da relação entre Aristóteles e Nietzsche, nem utiliza, como teria sido extremamente produtivo para este caso, as análises de Jaeger sobre a paideia aristotélica, nem - e é o que mais surpreende - as considerações do próprio Hadot. Por fim, tendo em conta o destaque que Verkerk deu nos capítulos antecedentes à influência dos pensadores helenísticos sobre Nietzsche, não se compreende, neste caso, o destaque dado agora a Aristóteles e não a uma análise comparativa, focada no próprio tópico da amizade, que disponibilizasse um quadro das relações entre Nietzsche, os estóicos e os epicuristas.

Finalmente, os últimos dois capítulos, Mulher, amor e os problemas de género da amizade em Nietzsche e Irigaray [Woman, Love and the Gendered Troubles of Friendship in Nietzsche and Irigaray] (pp. 125-151), e Raptar a mulher? Uma recepção agonística dos dons de Nietzsche (e Derrida) [Abducting Woman? An Agonistic Reception of Nietzsche's (and Derrida's) Gifts] (pp. 153-162), oferecem uma perspectiva sobre a relação entre a amizade e a concep- 
ção de Nietzsche da mulher. Entram aqui em jogo, principalmente, as reflexões de Luce Irigaray e de Jacques Derrida (Éperons. Les sytles de Nietzsche). Dialogando também com pensadoras transgénero, como Susan Stryker, Kater Bornstein e Julia Seran, ou com Judith Butler, Verkerk admite a possibilidade de substituir a equivalência entre mulher e verdade, feita por Nietzsche e sublinhada por Derrida, pela equivalência entre gênero e verdade. $\mathrm{O}$ próprio conceito de "mulher" em Nietzsche pode ser, tal como esclarecido por Derrida, retirado do fetichismo e interpretado através das mesmas técnicas de escrita de Nietzsche, a partir das quais o leitor pode, e até deve, reavaliar noções aparentemente fixas utilizadas pelo próprio autor. Simultaneamente, na condenação que ambos, Nietzsche e Derrida, fazem dos movimentos feministas das suas épocas, Verkerk lê um risco: "a polivalência trazida sobre a mulher pela leitura de Derrida de Nietzsche torna-a mais acessível aos filósofos homens, mas menos acessível para as mulheres, e em particular para aquelas que queriam competir com as habilidades dos filósofos homens como amigos agonísticos" (p. 156). Derrida destaca na forma como Nietzsche conceptualiza a mulher três modalidades: a mulher como falsidade, como verdade e como um poder afirmativo. Nos três casos, Verkerk esclarece a presença de uma reificação do feminino (cf. p. 160). Uma leitura alternativa, feita por Frances Nesbitt Oppel, é mencionada em sentido contrário por Verkerk, para afirmar a possibilidade de considerar, por sua vez, as expressões nietzschianas relativas às mulheres como formas de provocação tendentes ao objetivo de criticar qualquer metafísica de gênero. Por fim, dialogando com as pensadoras transgênero, Verkerk esclarece como a noção de "mulher" que provém deste âmbito acaba por - na sua abertura a uma multiplicidade tal que acaba por envolver, ao mesmo tempo, maneiras de viver e de ser fisicamente - ter um resultado muito próximo das consequências que se poderiam tirar das premissas nietzschianas, relacionadas com a crítica da metafísica, e, portanto, também da metafísica 
Notas sobre um estudo de fontes: Ribot, Nietzsche e a psicofisiologia francesa do século XIX

de gênero. $\mathrm{O}$ caráter androcêntrico que Nietzsche mantém ainda nas suas considerações sobre o feminino, colocando a amizade no quadro de uma relação masculina, apesar das suas considerações sobre o carácter aberto do selbst, revela, para Verkerk, os aspectos de formação patriarcal em que Nietzsche e todas as gerações até às últimas décadas, viveram. Também no caso das reflexões sobre Nietzsche da pensadora feminista Irigaray, as características destacadas na amizade feminina - caracterizadas por esta autora por uma extrema identificação no caso das mulheres - indicam a presença de uma abordagem ainda influenciada, para Verkerk, por modalidades patriarcais que, através do foco posto por Nietzsche nas formas agonísticas da amizade e na necessidade de tirar o Eros às formas impostas pelo cristianismo, é possível inverter. Ainda mais quando a filosofia contemporânea deve enfrentar uma mudança nos paradigmas tradicionais - que não são só os binários, de género - de viver. Virtudes como a cooperação, que estão inscritas no modelo tradicional da erótica feminina, podem ser tiradas do âmbito restrito de uma erótica patriarcal e utilizadas para ampliar o espectro de autossuperação e autosubjectivação partilhada que Nietzsche aponta como verdadeiro objetivo da amizade, vista como verdadeira prática em que a filosofia encontra as múltiplas, possíveis e sempre reimagináveis maneiras de viver.

Verkerk não aposta no apoio que às suas considerações poderia ter dado Foucault como intérprete de Nietzsche e da mesma tradição da amizade filosófica, porém, as suas conclusões acabam por ir ao encontro das reflexões do filósofo francês, sobretudo no que se refere à visão da amizade como prática filosófica e ao mesmo tempo como prática de subjetivação ético-política. Neste sentido, o livro poderia ter aproveitado algumas considerações sobre o caráter não privado da amizade, questionando, por exemplo, o debate sobre a comunidade e o comum que se desenvolveu nas últimas décadas, a partir das reflexões de Georges Bataille (2017), de Jacques Derrida (2003) e de Jean-Luc Nancy (2016) sobre Nietzsche e sobre o 
"nós" nietzschiano.

Contudo, o livro de Verkerk permite, numa época em que o conceito de amizade foi traduzido na aceitação de um contato numa rede social - ainda mais hoje, podemos dizer, pelas dificuldades inerentes à pandemia - interrogar o estatuto antropológico da amizade, pensando-o, através de Hadot e do mais recente pensamento feminista, como verdadeira técnica de vida, assim como era na Antiguidade, e não simplesmente como instrumento de fuga do quotidiano (cf. Verkerk , 2019, p. 2). O destaque da obra de Nietzsche é, nesse sentido, duplo: a exploração da noção nietzschiana de amizade implica a compreensão da prática da amizade como base, não simplesmente de novas formas de relacionamento, mas também de uma nova cultura e de uma humanidade capaz de olhar para si mesma através dos olhos de quem acompanha de perto não só os lugares mais inexplorados e os mais sombrios da existência humana, mas também os mais alegres. Isto é, uma cultura que possa ultrapassar as formas e as atitudes próprias do niilismo. Por outro lado, esta exploração permite abordar a amizade como prática filosófica e a filosofia - a própria filosofia de Nietzsche - como prática que só pode fazer sentido quando se vira para a experiência da vida: uma prática no interior da qual a amizade se torna técnica fulcral para a autossuperação agonística da nossa condição de agonizantes "últimos homens" (e mulheres) no niilismo ocidental. 
Notas sobre um estudo de fontes: Ribot, Nietzsche e a psicofisiologia francesa do século XIX

\section{Referências}

BATAILLE, G. Sobre Nietzsche. Vontade de Chance, Autêntica, Belo Horizonte, 2017.

DERRIDA, J. Políticas da amizade, Campos das Letras, Lisboa, 2003.

FOUCAUlT, M. A Coragem da Verdade: O Governo de Si e dos Outros 2: Curso no Collège de France 1983-1984, Martins Fontes, São Paulo, 2020.

HADOT, P. Exercícios espirituais e filosofia antiga, É Realizações Editora, São Paulo, 2014

NANCY, J.-L. A comunidade inoperada, 7Letras, Rio de Janeiro, 2016.

NIETZSCHE, F. W. Sämtliche Werke. Kritische Studienausgabe (KSA). Herausgegeben von Giorgio Colli und Mazzino Montinari. 15 Bände. Berlin: Walter de Gruyter, 1999.

VERKERK, Willow. Nietzsche and Friendship, Bloomsbury, London-New York, 2019.

Enviada: $15 / 09 / 2020$

Aceita: 15/10/2020 